\title{
From Classroom to Boardroom: How International Marketing Students Earn Their Way to Experiential Learning Opportunities, and the Case of the
}

\section{“Beyond Borders of a Classroom” Program}

\author{
Sylvain Charlebois (correspondence author) \\ Faculty of Business Administration, University of Regina \\ 3737 Wascana Parkway, Regina, Saskatchewan S4S 0A2, Canada \\ Tel: 306-585-4111 E-mail: sylvain.charlebois@uregina.ca \\ Robert Giberson \\ Associate Dean Operations and International Programs \\ Faculty of Business Administration \\ University of Regina, Canada
}

\begin{abstract}
Many marketing instructors recognize the challenge of conveying to students the realities of international marketing within the classroom. In 2004, a Faculty of Business designed a partnership between stakeholders known as "Beyond borders of a classroom". This program offers a unique experiential learning opportunity for undergraduate students majoring in marketing. The program is comprised of two successive semesters. Semester 1 is a fusion of a live case competition and a client-based project. Semester 2 is an exclusive, applied overseas internship experience. At the end of Semester 1, a group of students selected by a panel of practitioners and academics is offered an opportunity to travel to the specified country in Semester 2, and to apply the theories learned beforehand. All expenses are paid for by the program. Only students who win the competition in Semester 1 move to the advanced international marketing class in Semester 2. The program has sent students to the U.S., China, Australia and Ukraine. While student satisfaction is high, the program faces some challenges. Some recommendations are presented.
\end{abstract}

Keywords: International marketing, Live-case competition, Undergraduate studies, Experiential learning, Client-based projects. 


\section{Introduction}

The demand for international business education has grown worldwide (Webb et al. 1999; Clarke III and Flaherty 2002). Globalization of markets is one of the most significant forces impacting today's business environment. Companies from almost all nations of the world vie for a share of global markets, and the various pedagogical approaches that aim to encourage students to attain the knowledge needed for success must improve (Karns 2005). As this global economic growth continues, understanding marketing and buyer behavior in all cultures as marketing students becomes more critical.

Karns (1993) and Bridges (1999) note that marketing must explore hands-on, interactive, real-world learning activities. Since these studies, marketing educators have given considerably more emphasis to experiential learning activities (Gremler et al. 2000; Kennedy, Lawton, and Walker 2001; Elam and Spotts 2004; Smith and Van Doren 2004). In 2004, a Faculty of Business designed a unique client-based program in international marketing.

"The competition is one of the most unique learning opportunities for students in our country. The competition gives our business students an advantage over students of other programs and exposure to businesses that are looking for highly skilled graduates.

- Dean of the Faculty (Johnstone 2006a)

For learning to occur, students need to experience other cultures and practice marketing through challenging activities (Schuster et al. 1998; Duke 2000). The primary objective of the program is to raise student consciousness of market globalization's impact on all forms of business in the $21^{\text {st }}$ century. Marketing educators realize that to compete in today's job market, students must not only understand the concepts and discipline of international marketing, they must also appreciate how other areas of marketing are affected by globalization (Lundstrom, White and Schuster 1996; Toncar and Cudmore 2000). All learning activities of the program are focused on a project involving a company that plans to export a product or service from the local business area. The underlying inspiration is similar to a client-based project which is considered a powerful pedagogical tool by instructors (Lopez and Lee 2005). The program provides a framework for developing a comprehensive marketing plan suitable for implementation in an international setting. Its particular focus is on real-life experience, and on identifying and analyzing the unique cultural and environmental characteristics of single nations and/or global regions.

The program is comprised of two successive semesters. At the end of Semester 1, a group of students selected by a panel of practitioners and academics is offered an opportunity to travel to the specified country in the following Semester 2, and to apply the theories learned beforehand. The program allows students to more fully appreciate the subtleties of international marketing and trades. Only students who win the competition in Semester 1 move to the advanced international marketing class in Semester 2. While these types of programs exist at the graduate level, currently there are no comparable programs for undergraduate students. 


\section{Ml Macrothink}

Over the last two years, the program known as "Beyond borders of a classroom" has sent students to the United States, China, Australia, and Ukraine. These students have had the opportunity to get involved with small and medium-sized organizations, multinational corporations, and even one publicly-traded company. One project involved importing a product into the country from a foreign-based organization. All other organizations were locally-based.

In the remainder of the article, we present the stakeholders involved in the program. We then discuss the process behind the two semesters and the competition. Finally, we state some issues and concerns about the program and outline some directions for future research in marketing education.

\section{Beyond Borders of a Classroom}

Various stakeholders are involved with the "Beyond borders of a classroom" program (see Figure 1). The main stakeholders for this program are the students, the University, the Faculty of Business, the corporate partners, and the Business Trade and Export Partnership (BTEP).

Figure 1

"Beyond borders of a classroom" stakeholders

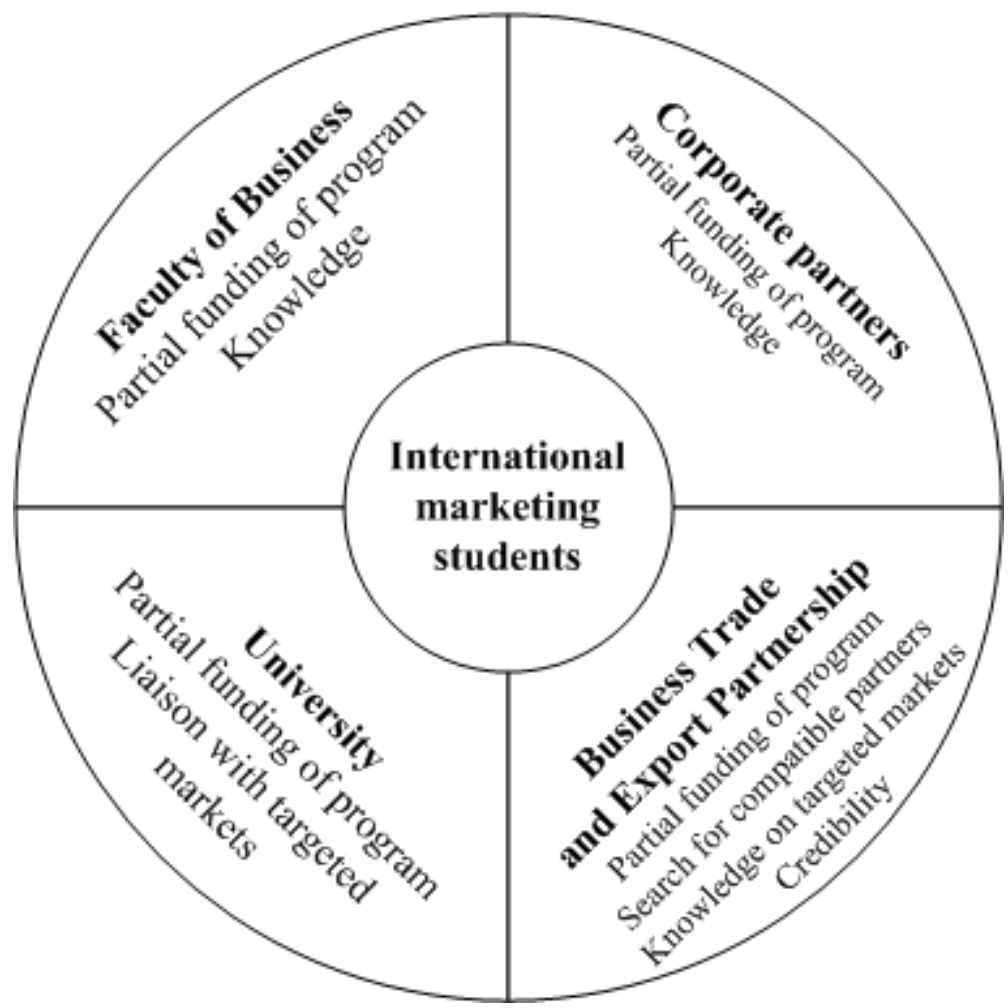

Students are at the centre of the program. Student learning objectives and interests influence every level of the program. Most students in the program are in their last year of their undergraduate degree in marketing. On average, approximately thirty students register for Semester 1. From the selection of the corporate partner to the presentation of the final report in Semester 2, the students' welfare and benefits are considered. While Semester 1 is 
regarded by many as one of the most demanding and rigorous undergraduate classes in the faculty, students who prevail in the competition are required to pay only their tuition fees for Semester 2. All travel and research expenses are paid for by the program. The University offers financial support for the program through the International Strategic Opportunity Fund for student mobility. The funding program is sponsored by the Office of International Cooperation and Development, which entertains many liaisons with several universities around the world. These global connections allow faculty members to access intelligence on targeted markets.

The Faculty of Business harbors the knowledge and capacity to teach international marketing at the university. It partially funds the program, and it also provides guidance and supervision to students for both semesters. Usually, one faculty member teaches the international marketing class (Semester 1) while a different faculty member is appointed to teach the advanced class and travel with the students (Semester 2). Teaching teams are preferred because of the challenges involved with grading projects, and the considerable time commitment (Razzouk, Seitz and Rizkallah 2003; Lopez and Lee 2005). As such, students have access to numerous points of views concerning the world, trade, and marketing. As well, faculty members expand their knowledge base, and gain valuable experience that can potentially inspire more research.

Obviously, corporate partners play a major part in the program. They are local-based, trade-oriented organizations that are actively seeking opportunities in new foreign markets. Many organizations have joined the program, and all must agree to the educational principles of the program. First, they must commit to the students' learning process. They have to make themselves available to answer questions, appoint an employee to assist students in their research, and set up a website to enable document sharing. Secondly, the program lasts a full academic year. Since the university environment is much less dynamic than the business milieu, corporate partners must adhere to the virtues of patience. Thirdly, the program is vigilant in terms of information management. Organizations are not allowed to use student work for commercial or strategic purposes unless they have a written permission to do so. Conversely, students also agree, at the beginning of Semester 1, to sign an agreement of confidentiality that is returned to the corporate partner. Students understand that information must be strictly confidential. Students are instructed not to disclose any business, personal, and/or otherwise confidential information to any person or organization without the written consent of a rightful representative of the corporate partner. Finally, the partial funding provided by corporate partners covers travel costs for students and additional costs for hiring interpreters, when required. Given that four to five students are offered participation in Semester 2, corporate partners are solicited to contribute between 15,000 USD\$ to 25,000 USD\$ to the program.

Lastly, BTEP is also involved in the program. BTEP is a public-private partnership led by industry and was established as a non-profit corporation in 1996 by the government. BTEP works in partnership with local businesses to maximize commercial success in global ventures. Its member companies occasionally receive custom export solutions and market intelligence. The partnership was created to provide trade development, custom market 
research and access to export financing for exporters. BTEP was integrated in the program because of its trustworthiness within and familiarity with the business community. In the program, BTEP predominantly supports the university and faculty in the selection process of corporate partners and in market intelligence for students.

\section{The Process}

The selection process for corporate partners may last several months. As well, the recruitment process is similarly rigorous. The faculty must actively seek projects. In live case studies and client-based projects, finding an appropriate business is the most difficult part of the planning process prior to starting the program (Elam and Spotts 2004). Unlike live cases or client-based projects where the nature of the project is essentially open and at no cost (Lopez and Lee 2005), it can be difficult to find a company willing to work with faculty, under unfamiliar circumstances, on an international project. While most organizations are eager to work with universities and students, the time and financial commitment required to participate in the program requires serious reflection by organizations on the prospects of the program. Some corporate partners may take months before committing. As a faculty and for students, it is preferred to have a corporate partner on board for the right reasons (Fox 2002). If no corporate partners qualify or are available for a given semester (Fall or Winter), Semester 1 is delivered normally, as prior to when the program started in 2004. If a corporate sponsor is found, the program lasts two full semesters (see Figure 2).

All students competing must obtain a valid passport. As mentioned earlier, all engagement work will be conducted in strict confidence and all students must sign a letter of confidentiality before starting the project. Throughout Semester 1, learning in the course is encouraged through a combination of lectures, class discussion, and textbook readings. During this time, internet research, case studies, completion of country-specific cultural analyses, and a comprehensive understanding of an international marketing plan for the targeted country are required. Also, students must assign themselves to groups. Group sizes vary from one semester to another, depending on what the corporate partner is looking for. In some cases, groups of five students were allowed. In other cases, individual students were allowed to submit a proposal on their own. Of course, group sizes have a significant impact on workloads for both faculty and students.

At the beginning of Semester 1, executives from the corporate partner are invited to present an official mandate to the class. That mandate becomes a significant learning thrust to everything that occurs in class. The scope of the mandate can either be broad or very specific to one component of a more extensive international marketing strategy (i.e. market segmentation, modes of entry, branding, or communications). Similar to client-based projects, the emphasis is on finding a balance that challenges students to the point that learning outcomes are maximized (Lopez and Lee 2005). 
Figure 2

"Beyond borders of a classroom" process

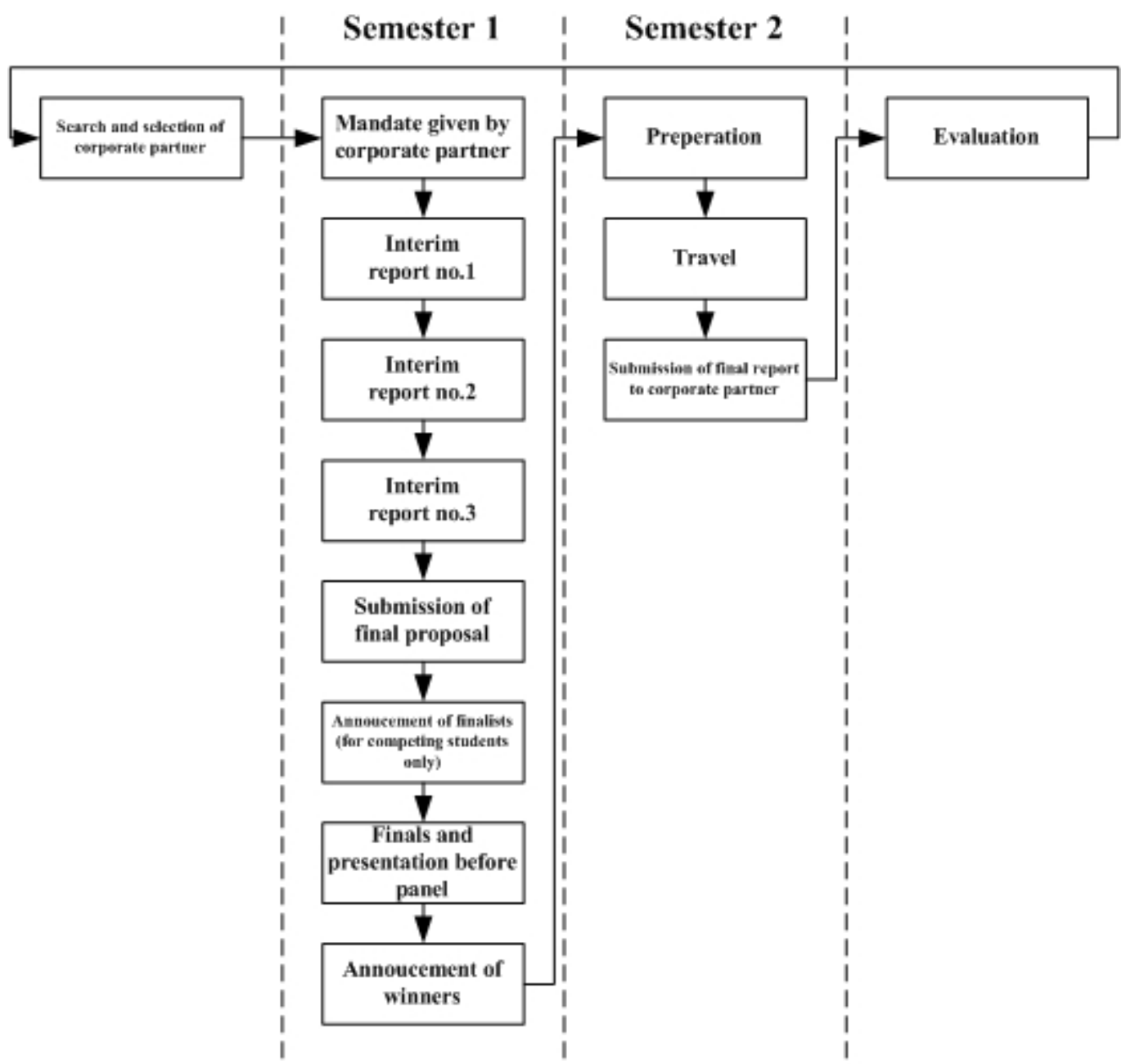

The mandate can be very demanding for many students, even for those in their last year of their undergraduate program. Semester 1 is broken down into three interim reports. A report is submitted every three weeks. This series of reports represents an incremental progression towards the final proposal. The purpose of these applied interim reports is to evaluate the student's understanding of the marketing concepts they are exposed to during Semester 1. Through these reports, students learn to link concepts with concrete situations in order to cope with the ambiguous and uncertain nature of mandates (Karns 2005). All interim reports are submitted by each student individually, whether or not students are submitting their final proposal in groups. The research activities for these reports, however, can be planned in groups and similar references can be used. These provisional reports are used as a build-up towards a more elaborate written strategy. The nature of these reports varies from one semester to the next, depending upon the mandate of that year.

Semester 1 is research intensive. Students are not asked to collect primary data at this stage and, therefore, ethical approval from the University's Research Ethical Board is not necessary. To assist students in their secondary data collection, and since all students are working on the 
same project, they are expected to become country experts. Although it is recognized that presentations are a less preferred class activity (Karns 2005), students are required to present an article about any industry, company, or country, as long as the article is relevant to the given mandate. Documents used for student presentations are posted on the course website. Following the presentation, a class discussion about the article follows. Students are also expected to gather current information on the assigned region and/or related industry. Students are expected to keep the class up-to-date - via written/verbal reports or presentations - on important developments, such as current events, in that particular region.

Once within the program, students have the freedom to not compete and may withdraw from the competition for personal reasons. Or, some may feel uncomfortable with the idea of competing against peers. Since the competition is not mandatory, each team that wishes to compete must submit a letter of intent to compete, should they make the finals. Writing such a letter ensures that students understand that if they are invited to present in the finals, but fail to win in the competition, their efforts are not compensated. Students who decide not to compete will get a final grade for their proposal, but their work will not be considered for participation in the next semester.

The final proposal should contain elements from the first three interim reports, as well as details about how to introduce the chosen product to the targeted market. Each competing group is also expected to formulate a strategy that shows how it expects to validate information from their deskwork, and how to collect primary data once it arrives in the targeted country.

Once all the proposals are received, the instructor and executives review the proposals independently. Each produce a list of participants that they feel are deserving of being invited to compete in the finals. Once both sides agree to a short list, the finalists are announced in class. Students on this list are then invited to present a 20-minute summary of their report to a jury, and answer any questions panelists may have for 10 minutes. The teams present their final projects to a panel of six judges. The projects are judged by three Faculty of Business Administration professors, one representative of BTEP, and two representatives of the corporate partner. The professors are chosen to represent various disciplines, rather than being restricted to marketing, because the program is intended to be interdisciplinary. Previously, the program invited professors in strategy, accounting, finance, human resources, organizational behavior, and small business entrepreneurship. As explained earlier, this presentation is not considered part of the final grade for Semester 1. Based on set criteria attached to the course syllabus of Semester 1, the students who offer the best presentations and respond well to questions are automatically registered into Semester 2. Similar to Semester 1, Semester 2 is worth three credits. The number of qualifying students differs from one semester to the next (see Table 1). 
Table 1

Past "Beyond borders of a classroom" projects

\begin{tabular}{|c|c|c|c|c|c|}
\hline Semester & $\begin{array}{c}\text { Location of } \\
\text { head-office }\end{array}$ & $\begin{array}{c}\text { Nature of } \\
\text { product }\end{array}$ & $\begin{array}{c}\text { Description of } \\
\text { business }\end{array}$ & $\begin{array}{c}\text { Number of } \\
\text { winning } \\
\text { students }\end{array}$ & $\begin{array}{c}\text { Targeted } \\
\text { market }\end{array}$ \\
\hline Fall 2005 & Local & $\begin{array}{c}\text { CRM for health } \\
\text { care clinics and } \\
\text { HRMs }\end{array}$ & SME & $\begin{array}{c}6 \\
(3 \text { teams })\end{array}$ & U.S.A. \\
\hline Winter 2006 & Local & Swine genetics & Multinational & 3 & China \\
\hline Fall 2006 & Local & Canola seeds & $\begin{array}{c}\text { Publicly-traded } \\
\text { company }\end{array}$ & $\begin{array}{c}4 \\
(1 \text { team) }\end{array}$ & Australia \\
\hline Winter 2007 & Lviv (Ukraine) & Glauconite & SME & & Canada \\
\hline
\end{tabular}

The primary objectives of Semester 2 are to increase students' understanding of the impact of national and regional culture on international marketing, and of issues involved with conducting international market research concerned with developing an international marketing plan for the corporate partner and market. In order to accomplish these goals, the student travels to the targeted geographic market, applies the theories learned during Semester 1, and follows their strategy for primary data collection. Ethical approval for their research is required at this point. A faculty member accompanies students during the trip. The corporate partner has the option of going with the group. Upon their return, students submit a report and present it to executives. Finally, a continuous evaluation process enables all stakeholders to assess learning outcomes and review results.

\section{Analysis}

The program is beneficial to all stakeholders involved. For students, the program caters to different learning processes such as concrete experience learning and abstract conceptualization (Kolb 1984). It also encourages different types of learners to excel and surpass cognitive difficulties (Elam and Spotts 2004). Similar to a live case study where students are asked to solve real business problems with the participation of key decision makers, students in the program work in a dynamic and interactive environment (Burns 1990; Gentry 1990). The program goes beyond the simple integration of real-world content.

"This project certainly made business become a reality. It's great when you can apply school lessons to a real life situation."

$$
\text { - Winner, Fall } 2005 \text { (Rediger 2005) }
$$

The competitive environment inspires the students to achieve excellence. Strong emotions are often apparent as the results are announced, since students invest a significant amount of time and energy in their projects. 
"It raises the bar a little bit. From what I saw last year, the students are really, unbelievably motivated to win this"

\section{- Instructor, Winter 2006 (McLeod 2006)}

The program also fosters connections between marketing and other disciplines in business. To have a competitive advantage in their proposals, students must employ concepts outside the realm of marketing. In essence, the international marketing program is interdisciplinary (Alden et al. 1991; Kaser 1998), and accordingly, judges with different backgrounds have supervised the finals. Notwithstanding these inclusive elements, the main emphasis of the program is marketing.

While the vast majority of students enjoyed successful learning experiences, some projects worked better than others. Throughout these projects, we applied improvements that have increased the quality of the program and enhanced corporate partners' outcome.

Notwithstanding the successes of our prior efforts, some aspects of the program would benefit from further development. The following sections identify and discuss some of the major issues that arose during our experiences with the program since its inauguration in 2004.

The competitive nature: The non-cost restrictive and competitive nature of the program greatly contributes to the quality of the work provided by the students. Many exchange programs that offer international experience incur costs to students (Toncar and Cudmore 2000; Clarke III and Flaherty 2002). Invitations for Semester 2 are offered to competitive students based solely on merit, not affordability. However, given that this is in fact a competition, most students are unwilling to disclose any strategic information they may have during class discussions, in front of other competitors. During Semester 1, facilitating discussions may be difficult, but not impossible.

"As the project has progressed, we can see the students being very careful about the questions they ask. They don't want to give away any competitive advantages."

- Corporate partner, Fall 2005 (Rediger 2005)

The instructor allows students to not answer a question during class discussion, if the student so desires. In doing so, their peers may notice that they might be missing an important piece of information, and may be enticed to do more research after class.

Media and confidentiality: The competitive nature of the program has attracted the attention of local media on several occasions. The media has been involved with every competition because the program exhibits a striking sense of realism, which is uncommon in university courses. The faculty and university are very careful to safeguard the confidentiality agreements between the class and the corporate partner. Only students that are in the class 
and not competing are allowed to watch the competition. The media is allowed to interview winners, participants and judges, once the results are released.

Sophisticated products: As outlined in Table 1, all projects were related to highly technical and sophisticated products. The program has yet to be involved with a consumer-oriented product. Given the nature of the local economy, this trend was predictable. Having students involved with highly complicated products increased the challenge.

"It was very difficult, especially since none of us knew anything about agriculture going in (to the competition). We had to learn the course material, and learn about Australia and canola at the same time."

- Winner, Fall 2006 (Johnstone 2006b)

The main objective of the program is to help students understand that the role of marketers is to create an exchange between supply and demand, regardless of what product is being imported or traded abroad.

Recruitment of students: Many organizations consider the program as a human resources initiative, as well as a marketing initiative. This program allows student to connect with the business community more directly.

"There is a need in the community for this type of program. There are lots of companies looking at new export markets, but they don't necessarily have expertise in marketing. Students want practical experience and this gives them an opportunity to test their mettle."

- Instructor, Fall 2005 (Rediger 2005)

Many of these connections have resulted in internships, even hires, and not just for winning individuals.

"This program attracts and retains the best and brightest this country has to offer."

- Corporate sponsor, Fall 2006 (Johnstone 2006a)

We are aware of at least ten students who have been hired by corporate sponsors. However, monitoring students' whereabouts after they have gone through the program is currently not possible. A system should be put in place in order to do so.

Workload for students: In the last two years, the curriculum of the program needed to be adjusted. Other faculty members felt that students were putting too much effort into their international marketing projects to the detriment of concurrent courses. In response, the mid-term exam was dropped, and more variety was added to class discussions. Students protested that a discussion about the same company and project every class became dull and repetitive. Faculty used other cases and examples, but still applied them to the mandate. Interim reports were added during the second mandate on swine genetics. Separate case studies were used during the first cycle and students felt that the final proposal demanded too 
much research at the last minute. With interim reports, students are now able to research the proposal throughout the semester. In addition, every student in the program had learned from upperclassmen in previous semesters about the rigors of working with real organizations seeking to export or import a product. Students registering in Semester 1 are much less surprised with the workload than previously.

Workload for instructors: Many universities tend to have international marketing for undergraduate students taught by a part-time professor, lecturer, or an instructor. Opening up a classroom to an organization for a full semester requires much work and dedication. Since organizations contribute significant funding to the project, they usually get quite involved in the process. The program needs organizations to be actively involved, with a high level of commitment. Some students also need assistance from the organization on a daily basis during the semester. As stated by Karns (2005), real-world learning activities inherently involve more uncertainty, unpredictable circumstances, ambiguity, and systemic orientations. For pedagogical and administrative reasons, such a program is not possible without the support of a full-time faculty.

Students and corporate partners welcome periodic and productive feedback. In addition, it is the role of faculty to manage expectations. Students and corporate partners may expect incompatible outcomes. Faculty has to let corporate partners know about students' limited capacity. In turn, students need to be told that while organizations are not expecting consultant-worthy proposals, they are expected to reach higher standards. Students are often intimidated by these sorts of projects. In some cases, instructors must regularly reassure and motivate students. Essentially, client-based projects are often overwhelming for an instructor (Lopez and Lee 2005), and this program is no exception.

Transition between Semester 1 and Semester 2: The transition between semesters was also a concern in some of the projects. The instructor that teaches Semester 1 establishes a rapport, a trustworthy relationship that creates a positive and rewarding experience for all involved. For the instructor managing Semester 2 without any knowledge about the project, the targeted market, or the organizations, carrying on with the project became a demanding task. At the beginning, we appointed a professor once the winners of Semester 1 were announced. In more recent projects, the program appoints a second instructor at the commencement of Semester 1 . That instructor is invited to attend Semester 1 classes, lunches, and meetings with the corporate partner. In doing so, the transition is much more manageable.

The use of the appropriate educational strategy in international marketing enhances the overall learning experience for students. The program addresses many of the concerns faced by universities when training talented international marketing students at the undergraduate level (Turley and Shannon 1999). The program helps students realize that an international marketing career is not beyond their reach.

"I now know that I want to do this as part of my career."

- Finalist, Fall 2005 (Rediger 2005) 
International marketing instructors may find some interesting insights in this paper, but we still have much to learn about the social contributions of the program. Further research should consider measuring the longitudinal impact of undergraduate marketing competitions such as the one prescribed in this paper, and how they prepare students for real-world challenges in the international arena.

\section{Conclusion}

Student satisfaction and course evaluations matter (Karns 2005). Students gain valuable self-assurance when they receive regular feedback that commends their hard work and points out areas for further improvement. This program provides an increase in self-confidence to many of the students that competed in the "Beyond borders of a classroom" program, whether or not they reached Semester 2. At this point, the program tends to attract enthusiastic, dedicated students. They are willing to put much effort into a rewarding experience, with no guarantees of ultimate success.

"It was worth it because so often in university you don't get the chance to see the impact of what you're learning. There was a higher standard placed on it because it wasn't just about going for a mark in the class, you really had to think of the needs of the company."

- Finalist, Winter 2006 (McLeod 2006)

The program also helps forge closer ties between the Faculty of Business Administration and the surrounding business community, which could lead to more collaboration. As stated earlier, business recruitment for this program is difficult, but the program is getting some valuable attention. Because of media coverage, other universities have since inquired about how to set up such a program.

The "Beyond borders of a classroom" initiative is consistent with the recent push toward active, experiential learning pedagogies (Karns 2005). This program is an amalgam between many learning pedagogies, including a live case study, a case/business competition, an internship, and a field trip. All are considered by many as great learning experiences (Smith and Van Doren 2004). This program may have created a combination of pedagogies that upholds a form of "transcendental learning": from classroom, to boardroom, and into the real world.

\section{References}

Alden, S., R. Laxton, G. Patzer, and L. Howrd. 1991. Establishing cross-disciplinary marketing education, Journal of marketing education, 13(Summer), pg 25-30.

Bridges, E. 1999. Experiential learning and customer needs in the undergraduate research course, Journal of marketing education, 21(1), pg 51-59.

Burns, A.C. 1990. The use of live case studies in business education: pros, cons, and guidelines. 


\section{Macrothink}

International Journal of Education

ISSN 1948-5476

2009, Vol. 1, No. 1: E3

In guide to business gaming and experiential learning, edited by James Gentry, pg 201-215, London, Nichols/GP publishing.

Clarke III, I. and T. Flaherty. 2002. Teaching internationally: matching part-time MBA instructional tools to host country student preferences, Journal of marketing education, 24(3), pg 233-242.

Duke, C. 2000. Study abroad learning activities: a synthesis and comparison, Journal of marketing education, 22(2), pg 155-165.

Elam, E.R., H. Spotts. 2004. Achieving marketing curriculum integration: a live case study approach, Journal of marketing education, 26(1), pg 50-65.

Fox, T. 2002. A case analysis of real-world systems development experiences of CIS students, Journal of information systems education, 13(4), pg 343-350.

Gentry, J. 1990. What is experiential learning? In guide to business gaming and experiential learning, edited by James Gentry, pg 9-20, London, Nichols/GP publishing.

Gremler, D., K. Hoffman, S. Keaveney, and L. Wright. 2000. Experiential learning exercises in services marketing courses, Journal of marketing education, 22(1), pg 35-44. Johnstone, B. 2006a. (Information not available to reviewers). Johnstone, B. 2006b. (Information not available to reviewers).

Karns, Gary L. 1993. Marketing student perceptions of learning activities: structure, preferences and effectiveness. Journal of marketing education, 15(1), pg 3-10.

Karns, Gary L. 2005. An update of marketing student perceptions of learning activities:

structure, preferences, and effectiveness, Journal of marketing education, 27(2), pg 163-188.

Kaser, K. 1998. The importance of an international marketing class, Business education forum, 53(2), pg 32-38.

Kennedy, E., L. Lawton, and E. Walker. 2001. The case of using live cases: shifting the paradigm in marketing education, Journal of marketing education, 23(2), pg 145-151.

Lopez, T. B., R. G. Lee. 2005. Five principles for workable client-based projects : lessons from the trenches, Journal of marketing education, 27(2), pg 172-188.

Lundstrom, W., S. White, and C. Shuster. 1996. Internationalizing the marketing curriculum: the professional marketer's perspective, Journal of marketing education, 18(Summer), pg 5-16.

McLeod, M. 2006. (Information not available to reviewers). 


\section{Macrothink}

International Journal of Education ISSN 1948-5476 2009, Vol. 1, No. 1: E3

Razzouk, N. Y., V. Seitz, and E. Rizkallah. 2003. Learning by doing: Using experiential projects in the undergraduate marketing strategy course, Marketing education review, 13 (2), pg 35-41.

Rediger, P. 2005. (Information not available to reviewers).

Scuster, C., P.R. Zimmerman, C. Schertzer, and P. Beamish. 1998. Assessing the impact of executive MBA international travel courses, Marketing education review, 3(3), 54-60.

Smith, L. and D. Van Doren. 2004. The reality-based learning method: a simple method for keeping teaching activities relevant and effective, Journal of marketing education, 26 (1), pg 66-74.

Toncar, M., and B. Cudmore. 2000. The overseas internship experience, Journal of marketing education, 22(1), pg 54-63.

Turley L. and R. Shannon. 1999. The international marketing curriculum: views from students, Journal of marketing education, 21(3), pg 175-180.

Webb, M., K.S. Mayer, V. Pioche, and L. Allen. 1999. Internationalization of American education, Management international review, 39(4), pg 379-397. 